\title{
The Simulation of Three Phase VSR Based on Space Vector Pulse Width Modulation
}

\author{
Lili Tang ${ }^{1, \mathrm{a}}$, Xianmin $\mathrm{Ma}^{1, \mathrm{~b}}$ \\ ${ }^{1}$ School of Electrical and control Engineering, Xi'an University of \\ science and Technology, Xi'an, 710054, China \\ atl12288@sina.com, ${ }^{b}$ maxianminphd@163.com
}

\begin{abstract}
.
The topology of Three-Phase PWM Voltage Source Rectifier (VSR) is introduced in this paper. The mathematical model in three-phase static and two-phase rotary coordinate system is built. According to the component of reference voltage vector in two-phase static coordinate, the sector and the action time can be calculated directly. Then, a three phase PWM rectifier model is established. The simulation results indicated that the dc-side can output stable voltage, verified the correctness and feasibility of the theory.
\end{abstract}

Keywords: Three Phase VSR; SVPWM; d-q model;

\section{Introduction}

SVPWM control strategy is a new control strategy via the space voltage vector (current Vector) switch the converter, which is put forward by Japanese scholars in view of the AC motor variable frequency drive [1]. The PWM rectifiers present in this paper have excellent features such as undistorted sinusoidal waveform, unit power factor, bidirectional energy flow and rapid dynamic response [2]. It is proved that the DC voltage utilization ratio of SVPWM is the highest, which is helpful to increase the inverter's output voltage. Applying SVPWM in rectifier, mainly because of high efficiency, rapidly response, etc.[3]. Therefore, Three-phase PWM rectifiers are popular in modern power electronics. 


\section{Model of Three-Phase PWM Rectifier}

The main circuit of three-phase PWM rectifier is shown in Fig.1.Here, $e_{k}, i_{k}(k=a, b, c)$ represent source voltage and the input current, $\mathrm{L}$ is the AC-side inductance and $\mathrm{C}$ is the DC-side filter capacitance.

To be convenient to analyzing, the three-phase VSR will be converted to the synchronous rotating $d-q$ coordinate system. Under the $d-q$ coordinate the mathematical model defined as:

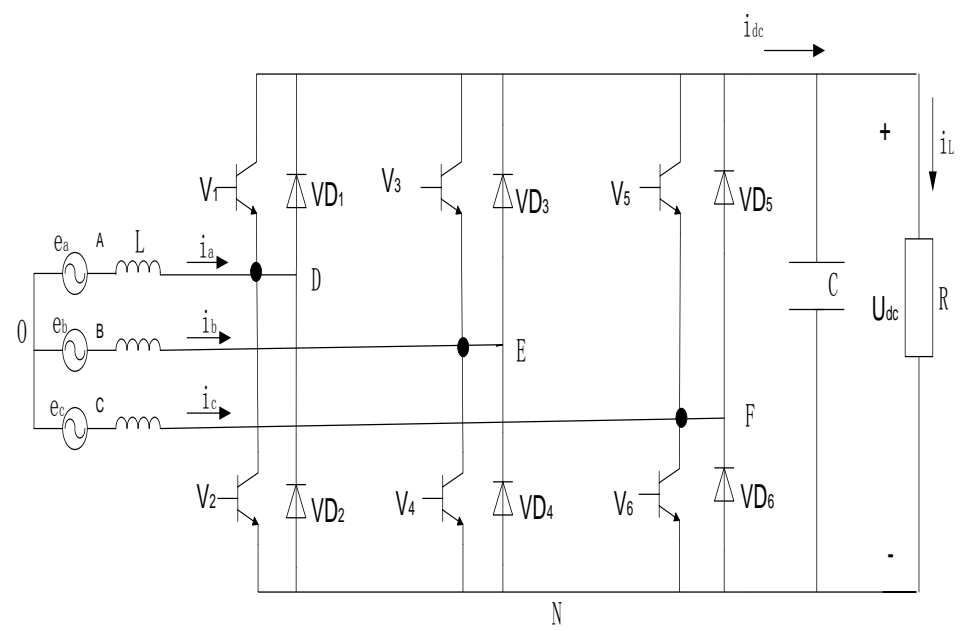

Fig.1.Main circuit of three-phase voltage source PWM Rectifier

$$
\begin{aligned}
& \left\{\begin{array}{l}
e_{d}=L \frac{d i_{d}}{d_{t}}+u_{d}-\omega L i_{q} \\
e_{q}=L \frac{d i_{q}}{d t}+u_{q}-\omega L i_{q} \\
\quad C \frac{d u_{c}}{d t}=I_{d c}-I_{L}
\end{array}\right. \\
& \text { Int this definition: } \\
& I_{d c}=3\left(s_{d} i_{d}+s_{q} i_{q}\right) / 2 ; u_{d}=s_{d} U_{d c} ; u_{q}=s_{q} U_{d c}
\end{aligned}
$$

\section{Principle of the SVPWM}

There are eight voltage space vectors, except the two zero vectors, the rest are non-zero and distributed on the complex plane [4,5]. When the target vector is in 
hexagon, the reference voltage vector can be synthesized through weighted average of the basic vector, as shown in Fig.2. The higher the switching frequency is, the rounder the trajectory is.

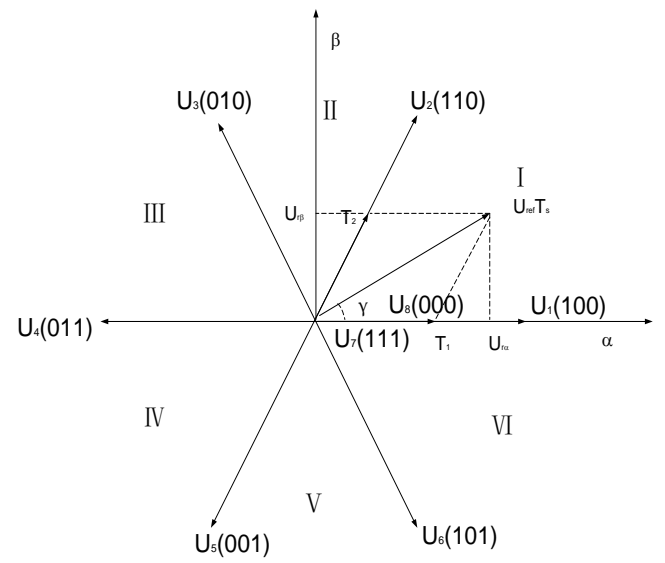

Fig.2. Diagram of space vectors of three-phase voltage rectifier

For example, in the first sector, the reference voltage can be synthesized in the two-phase static coordinate system [6], and the reference voltage can be expressed as:

$$
U_{\text {ref }} T_{s}=U_{1} T_{1}+U_{2} T_{2}
$$

Where, $T_{s}$ is switching period, $T_{1}$ and $T_{2}$ are the action time of $U_{1}$ and $U_{2}$.And then decomposed the equation 2, we can get Eq.3 and Eq.4.

$$
\begin{aligned}
& T_{1}=\sqrt{3} T_{s} \frac{\left|U_{r e f}\right|}{U_{d c}} \sin \left(\frac{\pi}{3}-\gamma\right) \\
& T_{2}=\sqrt{3} T_{s} \frac{\left|U_{r e f}\right|}{U_{d c}} \sin (\gamma)
\end{aligned}
$$

According to the Eq.3 and Eq.4, the action time $T_{1}$ and $T_{2}$ in a control cycle period can be calculated, the rest of vector are similar to the reference voltage.

The sector can be determined by the following rules:

$V_{\gamma 1}=U_{\beta}, V_{\gamma 1}>0$, then $A=1$, else $A=0$; 
$V_{\gamma 2}=\frac{\sqrt{3}}{2} U_{\alpha}-\frac{1}{2} U_{\beta}, V_{\gamma 2}>0$, then $B=1$, else $B=0$;

$V_{\gamma 3}=-\frac{\sqrt{3}}{2} U_{\alpha}-\frac{1}{2} U_{\beta}, V_{\gamma 3}>0$, then $C=1$, else $C=0$;

$N=A+2 B+4 C$

The corresponding relationship between $\mathrm{N}$ and sectors is shown in Table 1 . Table.1 The Relationship of Sector and N

\begin{tabular}{c|cccccc}
\hline$N$ & 3 & 1 & 5 & 4 & 6 & $\mathbf{2}$ \\
\hline Sector & I & II & III & IV & V & VI \\
\hline
\end{tabular}

\section{Determine the Time Switch Works}

$$
X=\frac{\sqrt{3} T_{S}}{U_{d c}} U_{\beta} \quad Y=\frac{\sqrt{3} T_{S}}{2 U_{d c}}\left(\sqrt{3} U_{\alpha}+U_{\beta}\right) \quad Z=\frac{\sqrt{3} T_{S}}{2 U_{d c}}\left(-\sqrt{3} U_{\alpha}+U_{\beta}\right)
$$

Switch operation time is put forward in table.2.

Table.2 Switch Operation Time

\begin{tabular}{ccccccc}
\hline sector & $\mathrm{I}$ & $\mathrm{II}$ & $\mathrm{III}$ & $\mathrm{IV}$ & $\mathrm{V}$ & $\mathrm{VI}$ \\
$T_{1}$ & $-Z$ & $Z$ & $X$ & $-X$ & $-Y$ & $Y$ \\
$T_{2}$ & $X$ & $Y$ & $-Y$ & $Z$ & $-Z$ & $-X$ \\
\hline
\end{tabular}

According to table 2, $T_{1}$ and $T_{2}$ in different sector can be obtained. Then the conduct time of $a, b, c$ phases can be calculated via the Eq.6 to Eq.8;

$$
T_{a}=\left(T_{s}-T_{1}-T_{2}\right) / 4
$$

$$
\begin{aligned}
& T_{b}=T_{a}+T_{1} / 2=\left(T_{s}+T_{1}-T_{2}\right) / 4 \\
& T_{c}=T_{b}+T_{2} / 2=\left(T_{s}+T_{1}+T_{2}\right) / 4
\end{aligned}
$$

\begin{tabular}{lllllll}
\hline sector & I & II & III & IV & V & VI \\
\hline
\end{tabular}




\begin{tabular}{ccccccc}
\hline $\mathrm{Tcm} 1$ & $\mathrm{~T}_{\mathrm{a}}$ & $\mathrm{T}_{\mathrm{b}}$ & $\mathrm{T}_{\mathrm{c}}$ & $\mathrm{T}_{\mathrm{c}}$ & $T_{b}$ & $\mathrm{~T}_{\mathrm{a}}$ \\
$\mathrm{Tcm} 2$ & $\mathrm{~T}_{\mathrm{b}}$ & $T_{a}$ & $\mathrm{~T}_{\mathrm{a}}$ & $\mathrm{T}_{\mathrm{b}}$ & $T_{c}$ & $\mathrm{~T}_{\mathrm{c}}$ \\
$\mathrm{Tcm} 3$ & $\mathrm{~T}_{\mathrm{c}}$ & $T_{c}$ & $\mathrm{~T}_{\mathrm{b}}$ & $\mathrm{T}_{\mathrm{a}}$ & $\mathrm{T}_{\mathrm{a}}$ & $\mathrm{T}_{\mathrm{b}}$ \\
\hline
\end{tabular}

\section{Simulation results}

Three-Phase SVPWM controller simulink simulation model of SVR is shown in figure 3. The models parameters is follow: power grid phase voltage's RMS is $220 \mathrm{~V}, f=50 \mathrm{~Hz}, L=5 \mathrm{mH}, C=2200 \mu F, U_{d c}=400 \mathrm{~V}, R_{L}=100 \Omega$.

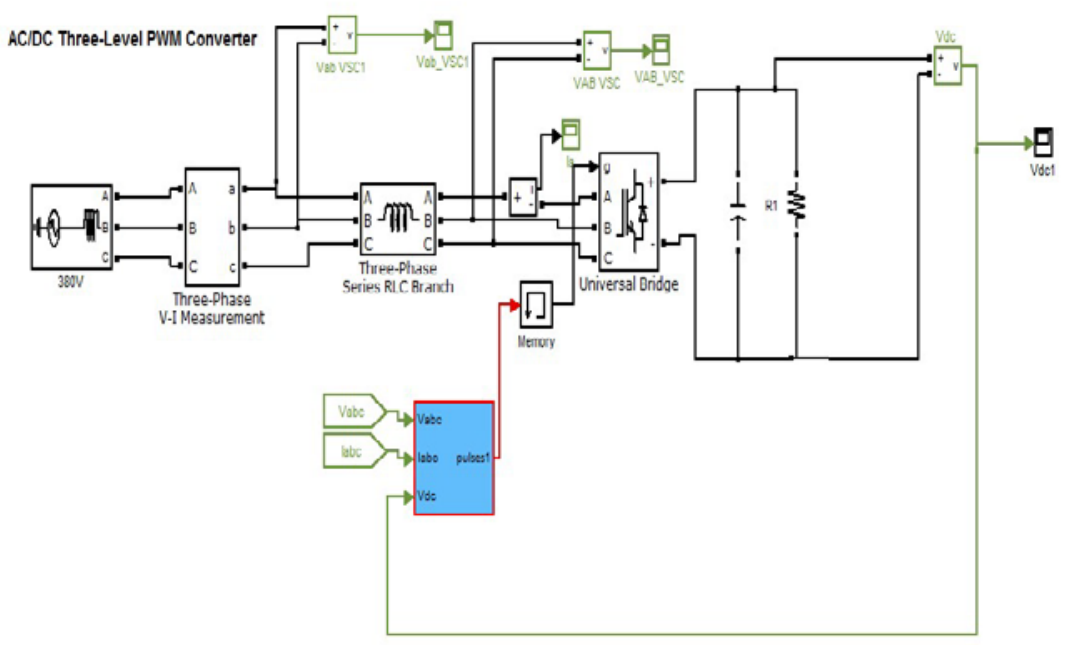

Fig.3. Three-phase SVPWM controller simulink simulation model of SVR

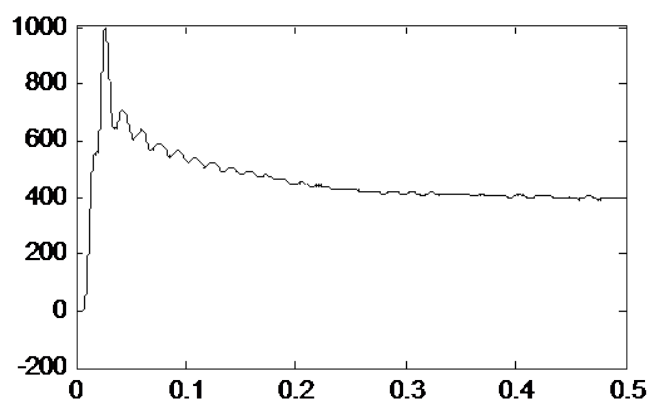


(a) DC output voltage

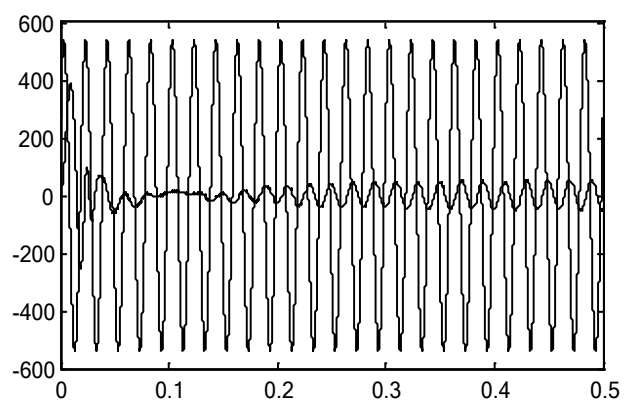

(b) A phase input voltage and current

Fig.4.Simulation result

The results of the simulation is shown in Fig.4, Fig.4(a) is the DC-side voltage, the DC-side voltage will reach $400 \mathrm{~V}$ within $0.2 \mathrm{~S}$, Fig.4(b) is the power grid voltage and input current of A phase. The result indicated that the DC-side voltage is stabile, and the validity and effectiveness of this strategy.

\section{Conclusion}

Based on the analysis of the space vector PWM, the model is established and simulated with the MATLAB. The simulation results show the control method is effective, it also provided a favorable guiding significance in hardware system design. We also find the overshoot of system is much bigger, and the disturbance is not mentioned. In order to reduce these defects, the dual-closed PI regulator will be considered in the future. 


\section{Acknowledgement}

In this paper, the research was sponsored by the Nature Science Foundation of China (Grant No. 51277149).

\section{References}

[1] Xing Zhang, Chongwei Zhang. PWM Rectifier And Control. Beijing[M],Machine Industry Publishing House,2012.

[2] LI Xiao-xi, SONG Jian-cheng, QU Bing-ni, GENG P-long, LIU Guo-rui. Design of Three-phase Unity Power Factor PWM Rectifier[J]. Industry and Mine Automation.2011:8:67-70.

[3] HAN Xiao-yi, Qiu Rui-chang. Model and Simulation of PWM Based on Space Vector Control [J].Electrical Measurement \& Instrumentation.2010:47(538):59-62.

[4] Ian Wallace, Ashish Bendre, Jonathan P. Nord and Giri Venkataramanan. A nity-power-factor three-phase PWM SCR rectifier for high-powerapplication in the metal industry[J]. IEEE Transactions on Industry Applications, 2002:38(4):898-908.

[5]ZHENG Zheng, JING Xiao-ping. A simplified algorithm for three-phase PWM rectifier based on SVPWM[J]. Electric Drive Automation. 2010:32(3):13-16.

[6] Silva J F.Sliding-mode Control of Boost-type Unity-powerfactor PWM 
Rectifiers [J].IEEE Trans. on Industrial Electronics.1999:46(3):594-603. 